\title{
Arquitetura Art Déco: um estudo sobre o seu valor para a história e memória da cidade de Passo Fundo/RS, Brasil
}

\author{
Art Deco architecture: a study of its value for the history and memory of \\ the city of Passo Fundo/RS, Brazil
}

Letícia Regina Lorenzi* Dirceu Piccinato Junior**

*Graduada em Arquitetura e Urbanismo pela Universidade de Passo Fundo (UPF) (2014). Mestre em Arquitetura e Urbanismo pela Faculdade Meridional (IMED) (2019). Docente na Graduação em Arquitetura e Urbanismo da Universidade Luterana do Brasil (ULBRA) Campus Carazinho
**Graduado em Arquitetura e Urbanismo pelo Centro Universitário Moura Lacerda (2001) e em Filosofia pelo Centro Universitário Claretiano (2009). Mestre (2012) e Doutor (2016) em Urbanismo pela Pontifícia Universidade Católica de Campinas. Docente na Graduação e na Pós-Graduação em Arquitetura e Urbanismo da Faculdade Meridional (IMED) / (RS)

\section{Resumo}

O presente artigo tem o objetivo de apresentar e analisar as edificações com características Art Déco situadas na região central da cidade de Passo Fundo/RS, representativas de transformações socioespaciais modernizadoras. A sua valorização e reconhecimento como patrimônio cultural é de fundamental importância para que os fatos urbanos dessa cidade permaneçam como história e como memória. No Brasil, a arquitetura Art Déco marcou significativamente o cenário das cidades entre as décadas de 1930 e 1950, sendo uma expressão de modernidade acessível às diversas classes sociais da época. Por isso, há muitas perspectivas de análise para essa arquitetura, particularmente na sua difusão no estado do Rio Grande do Sul, Brasil. A cidade brasileira de Passo Fundo, situada na região norte desse estado, possui um significativo repertório de arquitetura Art Déco em sua área central, no entanto, essa arquitetura não se encontra circunscrita sob a legislação preservacionista do poder público municipal. Tal conjuntura, carece de um debate acerca do valor patrimonial desses artefatos para a cidade pelo motivo desse conjunto arquitetônico ainda não ter sido relacionado no cadastro municipal de bens de valor histórico patrimonial, o que evidencia uma falta de compreensão do valor dessa arquitetura como representativa de um momento histórico da cidade. Esse cadastro é uma lista onde estão relacionados os bens de valor patrimonial da cidade de Passo Fundo/ RS.

Palavras-chave: Patrimônio Cultural. Arquitetura Art Déco. Legislação Patrimonial.

\section{Abstract}

This article aims to present and analyze buildings with Art Déco characteristics located in the central region of the city of Passo Fundo / RS, representing modernizing socio-spatial transformations. Its appreciation and recognition as cultural heritage is of fundamental importance so that the urban facts of this city remain as history and as memory. In Brazil, Art Déco architecture significantly marked the scene of cities between the 1930s and 1950s, being an expression of modernity accessible to the various social classes of the time. For this reason, there are many perspectives of analysis for this architecture, particularly in its diffusion in the state of Rio Grande do Sul, Brazil. The Brazilian city of Passo Fundo, located in the northern region of this state, has a significant repertoire of Art Déco architecture in its central area, however, this architecture is not circumscribed under the preservation legislation of the municipal government. Such a situation lacks a debate about the patrimonial value of these artifacts for the city because this architectural ensemble has not yet been listed in the municipal registry of assets of historical patrimonial value, which shows a lack of understanding of the value of this architecture as representative of a historic moment in the city. This register is a list where the assets of patrimonial value of the city of Passo Fundo/RS are listed.

Keywords: Cultural Heritage. Art Déco Architecture. Patrimonial Legislation. 


\section{Introdução}

$\mathbf{P}$ texto "Entre memória e história: a problemática dos lugares", a memória é vida, sempre carregada por grupos vivos e, nesse sentido, ela está em permanente evolução, aberta à dialética da lembrança e do esquecimento. Já a história é a reconstrução sempre problemática e incompleta do que não existe mais. A memória é um fenômeno sempre atual, um elo vivido no eterno presente; a história é uma representação do passado. A memória pendura-se em lugares, a história, em acontecimentos. Sob uma dimensão poética, pode-se considerar que é a memória que dita e a história que escreve.

À medida que desaparece a memória, nos sentimos em certa medida obrigados a acumular de forma religiosa vestígios, testemunhos, documentos, imagens, discursos, artefatos, sinais visíveis do que foi, como se esse conjunto devesse se configurar em prova em não se sabe que tribunal de história (NORA, 1993).

A arquitetura fundamenta-se com a materialização da cultura, sempre atrelada à evolução e à história das cidades. As décadas entre 1930 e 1950 apresentam uma grande produção de arquitetura Art Déco em diversas cidades brasileiras, entre elas Passo Fundo, sendo um sinônimo de modernidade e com extremo vínculo com o período industrial. Porém, essa arquitetura tão representativa é ainda pouco estudada, possibilitando que muitos conjuntos edificados se descaracterizem com o tempo, pela falta de valorização e reconhecimento de seu valor para a história dos lugares.

Desse modo, o presente artigo apresenta um levantamento das edificações com características Art Déco, particularmente as situadas na atual centralidade de Passo Fundo, ou seja, as localizadas entre a Avenida Brasil, ruas Morom e Paissandu. A escoIha dessas vias como objeto de estudo se fundamenta no fato de as mesmas apresentarem dinâmicas singulares e diferentes em relação à cidade. As três vias apresentam uma diversidade urbana de usos - moradias, comércios, serviços -, manifestando expressões de heterogeneidade e pluralidade. Tal situação pode ser observada, por exemplo, na conservação de alguns desses edifícios, os 
quais se mantêm atuantes na paisagem e no cotidiano da cidade.

Assim, o levantamento e análise dessas edificações visam contribuir para o reconhecimento de seu valor para a memória e a história de Passo Fundo, assim como um primeiro passo para o reconhecimento e a valorização desses bens patrimoniais.

\section{A Arquitetura Art Déco}

A arquitetura Art Déco possui vertentes nas artes e no design que dissipou a ornamentação dos séculos anteriores, trazendo em suas linhas simples a inspiração no presente e no futuro (LEMME, 1996)

O Art Déco compreendido como uma arte atingiu seu apogeu entre a Primeira e a Segunda Guerras Mundiais, primeiramente na Europa e Estados Unidos. Sua divulgação ao grande público ocorreu durante a Exposição de Artes Decorativas e Industriais Modernas realizada em Paris em 1925, onde foi vista em projetos de interiores, estamparia e tapeçaria, cerâmicas, vidros, joias, esculturas e luminárias (PIZZETI; SOUZA, 2008).

Os pesquisadores Conde e Almada (2000) consideram que o Art Déco pode ser definido como uma arte, como uma decoração, como uma manifestação das artes internacional, como uma expressividade industrial, pois esteve associada à nascente sociedade industrial, e como modernizante, onde sua imagem estava associada a tudo que poderia ser definido como tal: os arranhas céus, os automóveis e os cinemas, por exemplo.

O Art Déco difundiu-se em diferentes aspectos da vida cotidiana entre as duas guerras mundiais. Essa difusão se beneficiou da produção em massa para época, pois muitos objetos que eram confeccionados com matéria prima cara e rara foram copiados e fabricados mediante alternativas mais acessíveis para época (LEMME, 1996).

A arquitetura Art Déco inovou ao simplificar a geometria de seus elementos decorativos e na diversidade e atualização de suas referências ornamentais. Essa arquitetura também se inspirou na arquitetura desenvolvida pela Beaux-Arts, onde as regras de simetria, axialidade e hierarquia na distribuição da planta, expressas na ênfase do acesso principal e na divisão da fachada em base, corpo e coroamento, eram notadamente marcantes (CORREIA, 2010).

Flutuando por diversos temas decorativos, essa arquitetura incluiu motivos figurativos estilizados, elementos geométricos e formas curvas aerodinâmicas que poderiam ser inspiradas nas máquinas e/ou navios, bem como também em temas vinculados a culturas antigas e à linguagem clássica. A arquitetura Art Déco recebeu fomentos do cubismo, do futu- 


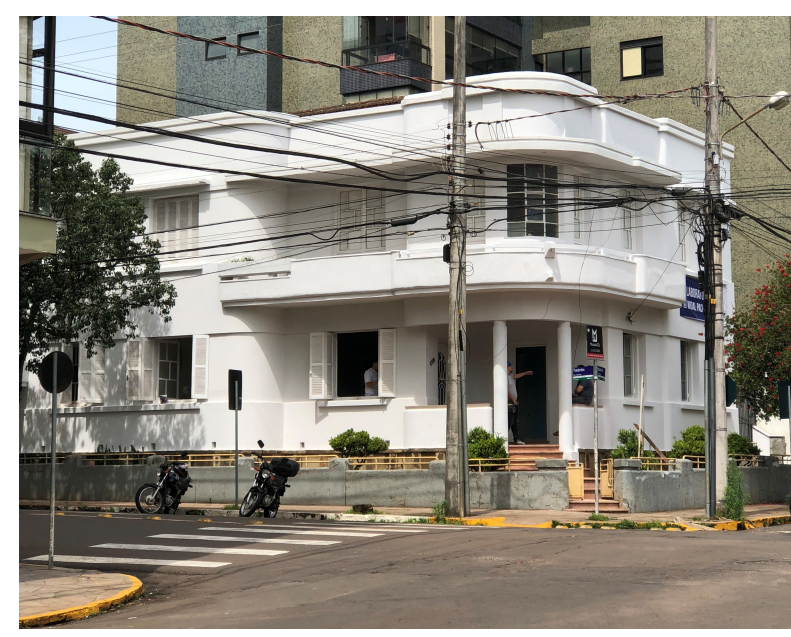

Figura 1. Residência com características Art Déco, localizada na esquina das Ruas Paissandu e Tiradentes, Passo Fundo/ RS. Nesta figura pode-se observar elementos figurativos e geométricos em sua fachada. Fonte: Autores, 2018. rismo, do expressionismo e outros movimentos das artes plásticas, assim como se apropriou de influências de arquiteturas anteriores e contemporâneas (CORREIA, 2008) (Figura 1).

O Art Déco foi o suporte formal para inúmeras tipologias arquitetônicas que se afirmavam a partir dos anos de 1930. Segundo Segawa (2014), nesta década a linguagem Art Déco estaria associada ao envoltório por excelência das grandes estruturas que romperiam os horizontes urbanos desenhados pelos homens, marcados, sobretudo nessa época, pela verticalidade das torres sineiras de igrejas ou de referenciais semelhantes. Tal conjuntura denota a importância da arquitetura Art Déco como representativa do processo de modernização do espaço urbano.

Para Conde e Almada (2000) essa diversidade de influências resultou em três diferentes concepções na arquitetura Art Déco, as quais pode-se identificar em três linhas: a primeira, mais seca e geometrizada, muito próxima do racionalismo modernista conhecida como escalonada ou ziguezague. A segunda, denominada como afrancesada, revela resquícios acadêmicos e ênfase na decoração e a terceira, com linhas sinuosas e aerodinâmicas, inspirada nas artes expressionistas, conhecida como streamline.
No Rio Grande do Sul, a arquitetura Art Déco surgiu em um contexto muito semelhante ao ocorrido no restante do país, em um momento de expansão dos principais centros urbanos e manifestações de uma vontade estética moderna. Sua manifestação foi influenciada pela geometrização e verticalização norte-americana, muito semelhante ao ocorrido no Uruguai. Sua principal disseminação aconteceu com a Exposição do Centenário Farroupilha no ano de 1935 em Porto Alegre (KÜMMEL, 2013).

Em centros urbanos menores ou cidades de porte médio, a adaptação aos códigos modernizantes aconteceu dentro das possibilidades e recursos de cada município. Para tanto, a percepção de modernidade estava atrelada à incorporação de novos modos de vida em que as mudanças no modo de morar, que passariam de casas térreas e sobrados para edifícios unifamiliares coletivos com altura entre 3 a 5 pavimentos, já era reconhecida como sinônimo dos novos tempos (KÜMMEL, 2013).

A arquitetura Art Déco mesclou aspectos inovadores e estabeleceu vínculo com o passado; a inovação situou-se na configuração geométrica de seus elementos decorativos e na diversidade e atualização das referências ornamentais. O vínculo com o passado permitiu a releitura de elementos da linguagem clássica da arquitetura. 


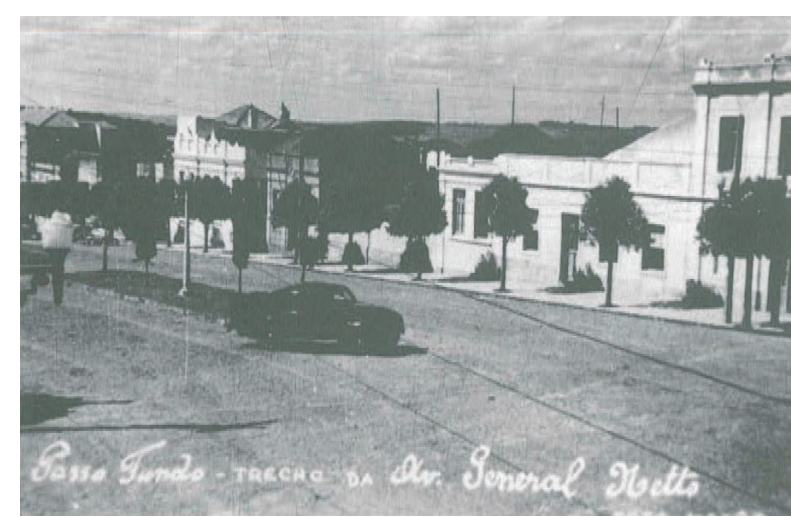

Figura 2. Moradias das tradicionais famílias passo-fundenses no trecho da Rua General Netto, entre a Rua Morom e Avenida Brasil em 1940. Fonte: Lech et al, 1999, p. 36

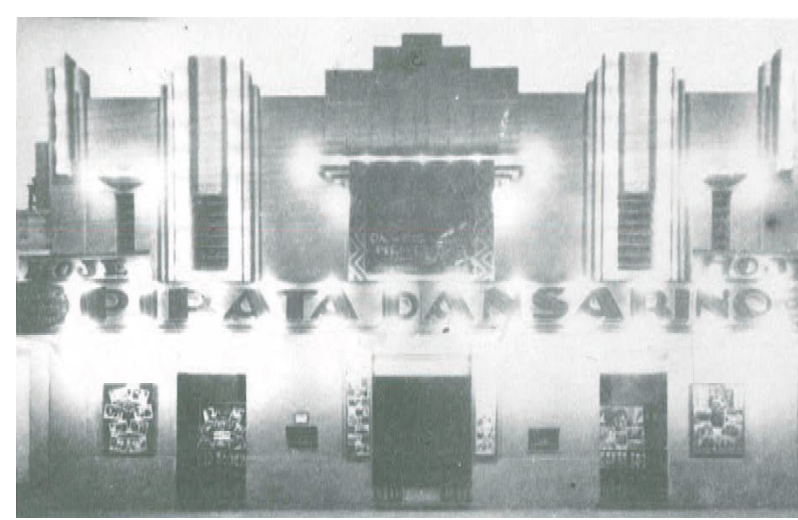

Figura 3. Cine Teatro Coliseu, ano 1937, na Avenida Genera Netto, Passo Fundo/RS. Pode-se notar as características do Art Déco na hierarquia do acesso centralizada na fachada na simetria da distribuição das aberturas e ornamentos. O Cine Coliseu foi destruído por um incêndio; mais tarde, em seu lugar foi erguido o Cine Real. Fonte: Lech et al, 1999, p. 162.
As transformações socioespaciais modernizadoras em Passo Fundo entre as décadas de 1930 e 1950

Passo Fundo, localizado no norte do estado do Rio Grande do Sul, no planalto médio, configura-se como um dos municípios mais importantes do estado, sendo o $12^{\circ}$ mais populoso, com cerca de 201.000 habitantes (IBGE, 2018). A cidade se destaca como centro regional pela oferta de serviços, principalmente de saúde e educação superior.

Ferreto (2012) afirma que no início do século XX o centro da cidade se desenvolvia entre a estação ferroviária e a Avenida Brasil, sendo a Rua General Netto o principal eixo de conexão da cidade. Outras ruas já se destacavam naquele período, como a Bento Gonçalves, a Morom, a Independência, a Capitão Eleutério e a General Canabarro, nas quais se localizavam os tradicionais estabelecimentos comerciais da cidade.

A organização do espaço urbano se deu em virtude dos interesses ligados ao desenvolvimento econômico do município, tendo sua região central formada pela elite local que tinha acesso à posse de propriedades urbanas, principalmente em torno da Praça Marechal Floriano, devido à crescente valorização imobiliária (KNAK, 2013) (Figura 2).
Passo Fundo, assim como as demais cidades brasileiras, passou a contemplar em seu espaço intraurbano um elemento vital para os rumos da modernização: a ferrovia. De certo modo, o complexo ferroviário composto pela linha e estação também trazia no seu conjunto novos modos de viver e novas tecnologias. Tal conjuntura possibilitou a transformação socioespacial urbana, o que significou para a cidade novas construções que se traduziram em uma arquitetura racional e moderna para a época.

O início do século XX é lembrado como a época em que a cidade encontrou a sua modernidade. As ruas ganharam iluminação por lâmpadas elétricas, houve a instalação da rede telefônica, a presença do primeiro banco e do primeiro cinema, entre outros movimentos que mudaram a paisagem urbana (MACHADO; MIRANDA, 2015) (Figura 3).

Gosch (2002) relata que, a partir da década de 1920, é perceptível a mudança na escala e na qualidade das edificações. Foi um momento de grandes modificações no espaço urbano, tendo início o processo de verticalização da área central marcado pela construção do Edifício Lângaro em 1942, sendo este edifício um dos principais fatos urbanos que ajudaram a construir a imagem moderna de Passo Fundo (Figura 4). 

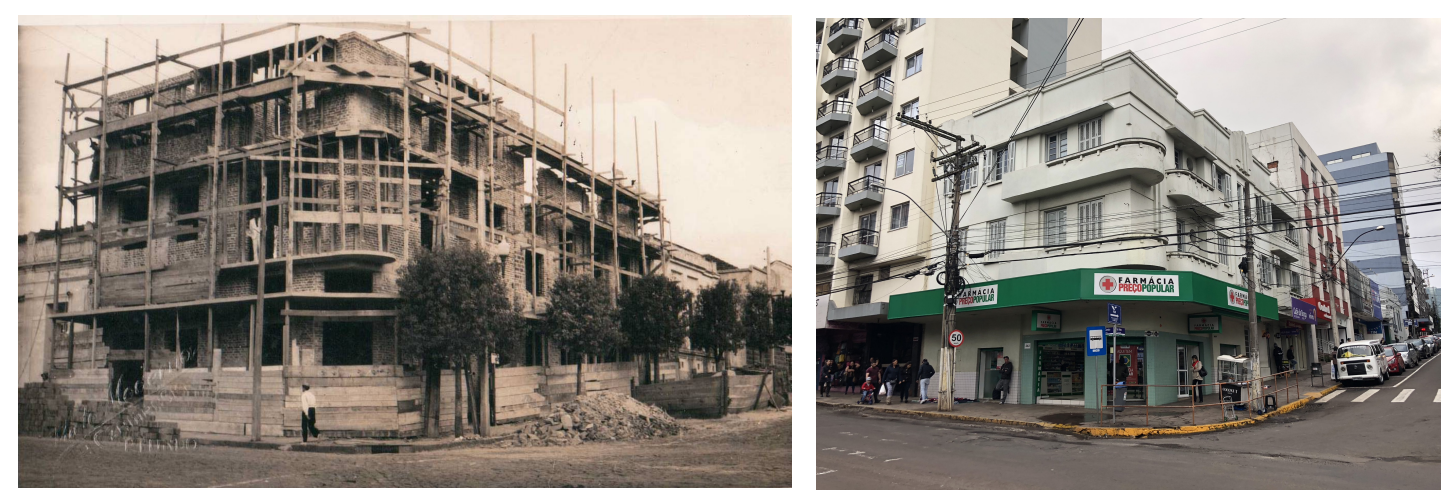

Figura 4. Edifício Lângaro em sua construção no ano de 1942. À esquerda o edifício em construção, projetado segundo uma estética Art Déco pelo arquiteto Annito Petry. À direita o edifício na atualidade. Fonte: Acervo Fernando Canali Lângaro e autores, 2018.

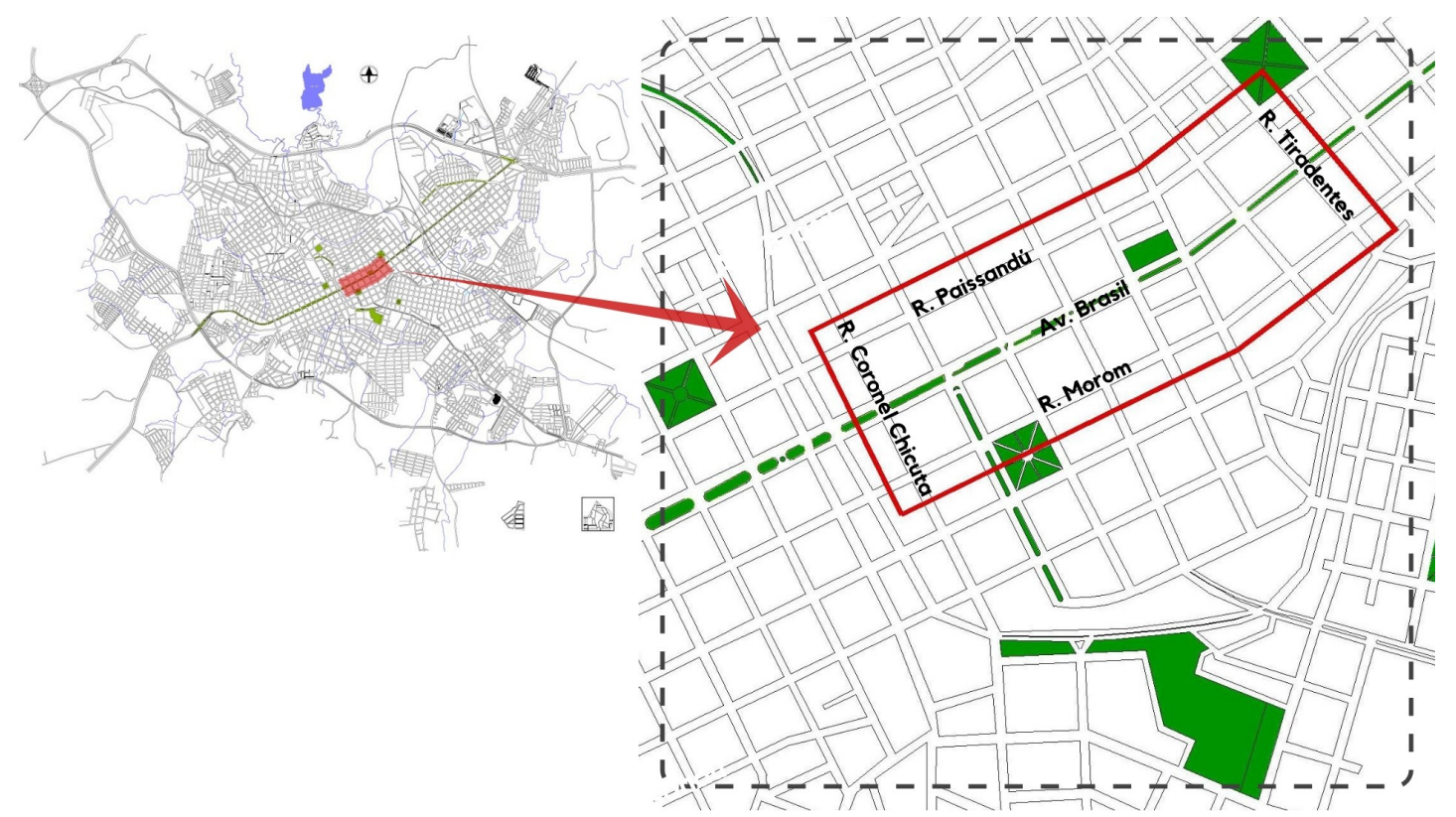

Figura 5. Mapa com a localização e delimitação da área de estudo situada nas testadas da Av. Brasil, Ruas Mo rom e Paissandu e entre as paralelas Ruas Coronel Chicuta e Tiradentes. Pode-se notar a centralidade da área de estudo em relação ao mapa da cidade de Passo Fundo. Fonte: Lorenzi et al, 2019.
Confirmando esse ideal modernizante e importante do processo de verticalização da cidade com a construção do edifício Lângaro, o jornal de circulação local "O Nacional" relatou no dia 28 de abril de 1942 que "Acentúa-se, em Passo Fundo, uma fase de importantes construções que, sobremaneira, contribuirão para o embelezamento e progresso da cidade". O projeto arquitetônico, segundo o referido jornal, foi desenvolvido pelo arquiteto Anito Petry e pelo seu auxiliar, Ernesto Delvaux (ACENTÚA-SE..., 1942, p. 3, grifo nosso).

A reportagem descreve que apesar da situação que atravessava na época, Passo Fundo como uma importante cidade do Rio Grande do Sul, continuava se movimentando e um grande número de prédios estava sendo erguido em diversos pontos da cidade (ACENTÚA-SE..., 1942, p. 3).

O Edifício Lângaro possui interessantes características do Art Déco, entre elas destacam-se: as sacadas curvas, janelas circulares que remetem aos navios, a simetria na fachada na repetição das janelas e sacadas, a marcação do acesso com a circulação vertical do edifício e elementos decorativos com linhas simples e geométricas.

A cidade de Passo Fundo, nas décadas de 1930, 1940 e 1950, apresentou uma expressiva produção de arquitetura com características Art Déco, tendo o Edifício Lângaro como um dos seus exemplares mais significativos. 
1. Esse estudo configura-se como um inventário provisório que foi elaborado em dois momentos: Um primeiro inventário aconteceu no ano de 2008 , e no ano de 2018 , houve a atualização dos dados. Esse trabalho foi desenvolvido pelo Núcleo de Arquitetura e Desenvolvimento Urbano e Comunitário (Naduc) da Universidade de Passo Fundo (UPF) em uma parceria com a Prefeitura Municipal de Passo Fundo e a Fundação Universidade de Passo Fundo. Disponível na Prefeitura Municipal de Passo Fundo.
Diante das informações expostas sobre o Art Déco e sobre Passo Fundo, a delimitação da área de estudo ocorreu em função de alguns critérios, sendo o primeiro deles a atual centralidade da cidade, tomando por base os levantamentos do pesquisador Diego Ferreto (2012), em que ele identifica o centro principal por apresentar uma grande oferta de comércio e serviços diversos.

A partir disso e também considerando a presença de edificações com alguma característica Art Déco, delimitamos então a área de análise junto às testadas da rua Paissandu, da Avenida Brasil e da Rua Morom, especificamente entre as vias paralelas Rua Coronel Chicuta e Rua Tiradentes (Figura 6). Essas três primeiras vias apresentam dinâmicas e articulações diferentes em relação à cidade. A Rua Paissandu apresenta-se como uma via com predominância de serviços relacionados à área da saúde; a Avenida Brasil, principal via articuladora da cidade e de importante valor histórico para a formação da cidade, apresenta uma variedade de usos, como o residencial, institucional, serviços, educação e comércio popular; e a Rua Morom, uma via bem arborizada, com uso predominantemente residencial, serviços e comércio de alto padrão.

Essa configuração da dinâmica espacial e de usos denota o adensamento dessa área. Processada pela verticalização e construções singulares em concreto e demais materiais que se caracterizaram como signos de progresso e modernização, inseridos em lotes definidos por padrões de divisão fundiária do período Imperial.

A identificação das edificações com características Art Déco foi realizada por meio de deslocamento peatonal ao longo dessas vias e também pelos estudos de Gosch (2002), Kramer e Waihrich (2007), Diniz e Almeida (2017) e pelo Estudo para Tombamento de Patrimônio Arquitetônico, Histórico e Paisagístico de Passo Fundo (2012) ${ }^{1}$. Tais estudos apontam algumas dessas edificações como pertencentes a esse léxico arquitetônico (Figuras 7 e 8).

Nesse cenário das 18 construções conforme o léxico Art Déco, tomando como parâmetro as condições de conservação, destacam-se: a Agência dos Correios (número 1), residência unifamiliar (número 8), outra residência unifamiliar (número 13), Casa de Apoio e Pousada (número 15) e a última residência unifamiliar da listagem anterior (número 18). A escolha dessas edificações para a contextualização da temática deu-se também em razão do volume de dados levantados acerca delas.

A Agência dos Correios (número 1) está situada na esquina da Rua Morom, esquina com a Rua Coronel Chicuta. Essa edificação possui um jogo de volumes com formas puras em sua composição. Ela possui frisos lisos na platibanda e na moldura das 

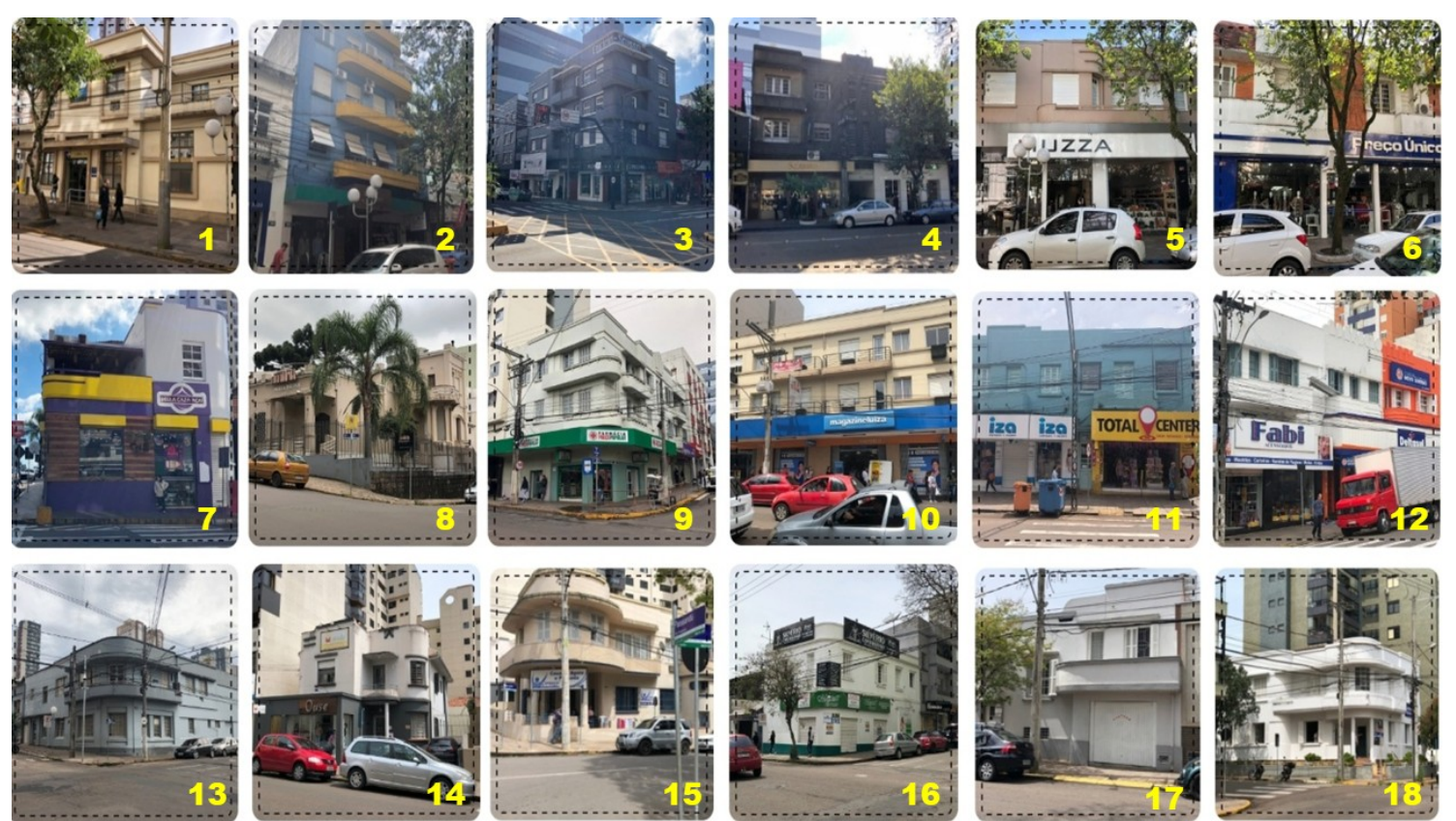

Figura . Fotografias das 18 edificações levantadas. Fonte: Lorenzi et al, 2019.

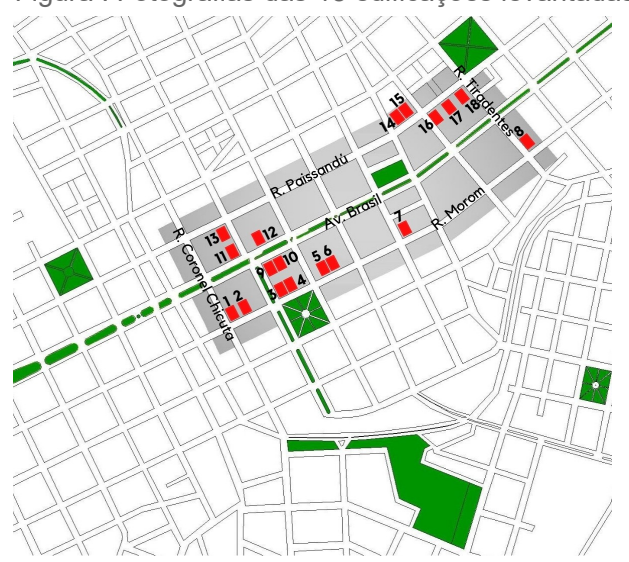

Figura . Mapa de localização das edificações identificadas com características Art Déco situadas na área em estudo. Fonte: Lorenzi et al, 2019.

usjt • arq.urb • número 27 | janeiro - abril de 2020 esquadrias, além de uma marquise que marca o acesso principal. Hoje a Agência se encontra em bom estado de conservação, mantendo seu uso e características originais.

A residência unifamiliar (número 8) está localizada na esquina da Rua Morom com a Rua Fagundes dos Reis. Essa residência mescla do Ecletismo as colunas de acesso, os arcos marcando o vão de algumas aberturas, os frisos decorativos e o coroamento da platibanda. Quanto ao Art Déco observase a valorização da esquina com o seu volume composto por formas puras, a tripartição da fachada, escalonamento do coroamento e os elementos decorativos. Nela hoje funciona uma pizzaria.

A Casa de Apoio e Pousada (número 15), anteriormente uma residência unifamiliar, está situada na Rua Paissandu, esquina com a Rua Silva Jardim. A esquina dessa edificação é marcada por um significativo volume arredondado marcando o acesso principal. Ela está distribuída em três níveis devido a topografia do terreno, situação que Ihe permitiu a configuração de um escalonamento de sua forma. As suas sacadas arredondadas são acompanhadas pelas marquises em concreto e frisos lisos na platibanda.

A residência familiar (número 18), hoje nela funciona um laboratório de clínicas, está localizada na es 
quina da Rua Paissandu, esquina com a Rua Tiradentes. A forma retangular com leve curvatura no acesso principal valoriza a esquina e evidencia a hierarquia de acesso. $O$ volume dessa edificação apresenta-se de forma proporcional. Além da simetria na distribuição das aberturas, verifica-se a divisão da fachada em base, corpo e coroamento. Recentemente ela passou por uma reforma, mantendo as características Art Déco.

O movimento econômico e cultural que a ferrovia trouxe a Passo Fundo possibilitou que a cidade se modernizasse segundo os importantes centros urbanos brasileiros. Nesse bojo a arquitetura Art Déco tornou-se o registro principal da sociedade local.

\section{As políticas patrimoniais da cidade de Passo Fundo/RS}

Podemos considerar os fatos urbanos como elementos estruturadores da cidade que pertencem à memória coletiva, ou seja, são elementos de valor e significado para uma sociedade. A partir dos fatos urbanos, podemos compreender os fenômenos das permanências e rupturas dos monumentos ou fragmentos do tecido urbano. Exposto isso, tornase importante considerar as questões relativas ao patrimônio cultural como responsáveis pela construção da cidade (EDELWEISS, 2016).
No Brasil a preocupação com o patrimônio nacional começou a ser assimilada após a divulgação da Carta de Atenas, em 1931. Todavia, antes mesmo da repercussão dessa carta, o escritor Mário de Andrade já iniciava sua busca por um projeto para 0 patrimônio nacional, pois entendia que a manutenção das obras arquitetônicas existentes garantiria a formação de uma identidade estética nacional (SALVADOR 2012)

No ano de 1936, Mário de Andrade aceitou o convite do então Ministro da Educação e Saúde, Gustavo Capanema, para redigir o anteprojeto de criação do futuro SPHAN - Serviço do Patrimônio Histórico e Artístico Nacional, criado em 13 de janeiro de 1937, por meio da Lei $n^{\circ} 378$, assinada pelo então presidente Getúlio Vargas, atual IPHAN - Instituto do Patrimônio Histórico e Artístico Nacional (IPHAN, 2015).

O IPHAN, até os anos de 1960, foi a instituição executiva do patrimônio cultural no Brasil; a partir de então, as unidades da federação e alguns municípios institucionalizaram suas agências de patrimônio cultural com o intuito de descentralizar as atividades de eleição de bens culturais significativos para os estados e municípios. Contudo, foi a partir de 1990, em virtude da Constituição Federal de 1988, que se outorga maior autonomia aos estados e municípios para que esses entes passassem a se responsabili- 
zar, conjuntamente com o IPHAN, pelo patrimônio cultural local (ALMEIDA, 2017).

Complementando essa ideia, Edelweiss (2016) aponta que no contexto contemporâneo brasileiro o Estatuto da Cidade e a Constituição Federal enfatizam a função social da propriedade. Nessa perspectiva, é a partir da função social do território que a cidade passa a assumir o interesse público e a buscar o bem-estar coletivo e a justiça social e nesse âmbito podem ser compreendidas as políticas de patrimônio, pois o patrimônio cultural é de interesse público e pertencente à coletividade.

Sobre algumas iniciativas em prol da preservação patrimonial, Edelweiss (2016) aponta exemplos de instrumentos utilizados para tal fim, como o inventário patrimonial, a determinação de áreas especiais de interesse cultural e o tombamento. Os dois primeiros são também instrumentos não apenas de preservação, mas de planejamento urbano. Nesse sentido, os valores de interesse cultural estão presentes na intenção e no planejamento de conservação dos valores da memória coletiva. Já o tombamento possui um caráter excepcional, "uma vez que estabelece um suposto congelamento temporal de monumentos, os quais, avalia-se, devem ser preservados para a eternidade" (EDELWEISS, 2016, p. 156).
Ao admitir que o inventário possa ser compreendido como um documento histórico que discrimina o que interessa manter para a posteridade, é possível reconhecer a importância dos critérios que norteiam a sua elaboração, assim como o efeito desencadeado por sua realização, justamente por constituir um instrumento indispensável de identificação e catalogação que permite individuar não apenas os artefatos materiais, mas também as memórias e histórias das quais esses objetos são portadores (ALMEIDA, 2018).

O inventário, assim como o próprio conceito de patrimônio, necessita ser compreendido mediante um conceito alargado. É fato que é preciso inventariar para poder proteger, mas não mais sob a ótica do objeto isolado. Para Leonardo Barci Castriota (2009) esse instrumento deve avançar para uma perspectiva de conjunto, ou seja, uma dimensão urbana, o que, consequentemente, permite abordá-lo a partir de uma visão dinâmica. Nesse sentido, poderão ser estabelecidas propostas de preservação integradas com a política urbana geral, utilizando-se do inventário não somente como instrumento de registro, mas como um efetivo instrumento de controle do desenvolvimento da paisagem urbana.

A cidade de Passo Fundo possui legislação patrimonial específica, representada pela Lei $n^{\circ} 2.997$ 
de 06 de janeiro de 1995, que dispõe sobre a proteção do patrimônio histórico-cultural, paisagístico e natural do município de Passo Fundo e dá outras providências:

Art. $1^{\circ}$ Constitui o Patrimônio Histórico-Cultural, Natural e Paisagístico do Município de Passo Fundo o conjunto de bens móveis e os espaços existentes em seu território que, por sua vinculação a fatos pretéritos memoráveis, a fatos atuais significativos, por seu valor cultural ou natural, ou por sua expressão paisagística, seja de interesse público preservar e proteger contra ações destruidoras (PASSO FUNDO, 1995).

No seu artigo $2^{\circ}$, ela estabelece que "os bens a que se refere o artigo $1^{\circ}$ somente passarão a integrar o Patrimônio Histórico-Cultural, Natural e Paisagístico do Município depois de inscritos, separada ou agrupadamente no livro do tombo respectivo" (PASSO FUNDO, 1995).

O artigo $5^{\circ}$ estabelece o que considera patrimônio cultural e histórico:

I - os monumentos: obras arquitetônicas, de escultura ou de pintura monumentais, elementos ou estruturas de natureza arqueológica, grupos de elementos que tenham um valor excepcional do ponto de vista da história, da arte ou da ciência;

II - os conjuntos: grupos de construções isolados ou reunidas que, em virtude de sua arquitetura, unidade ou integração na paisagem, te- nham um valor excepcional do ponto de vista da história, da arte ou das ciências;

III - os lugares notáveis; obras do homem ou obras conjugadas do homem e da natureza, bem como as zonas, inclusive lugares arqueológicos, que tenham valor excepcional do ponto de vista histórico, etnológico ou antropológico (PASSO FUNDO, 1995).

Refletindo sobre o artigo $5^{\circ}$ da lei patrimonial da cidade em estudo pode-se ponderar que ela não estabelece critérios, normas que se possa identificar um artefato de valor cultural para a cidade conforme o passar do tempo. Situação bem diferente acontece com a cidade de Bento Gonçalves, como se poderá observar a seguir. Só para concluir essa reflexão a Lei nº 2.997 de 1995 legisla sobre o tombamento e sobre os efeitos a que os bens patrimoniais e os tombados provisoriamente subordinam-se, deixando em aberto alguns aspectos desse contexto, como, por exemplo, a valorização e preservação do patrimônio imaterial de Passo Fundo/RS.

A proteção do patrimônio histórico, artístico e natural ocorre com a inscrição dos bens de natureza material no livro do tombo. O Decreto $n^{\circ} 134 / 2013$ regulamenta o Artigo $2^{\circ}$ da Lei $n^{\circ} 2.997$ em que se estabelece que o livro tombo será único e que a inscrição dos bens deverá contemplar as especificações, de acordo com o tipo do bem (PASSO FUNDO, 2013). 
Na lista das 24 edificações tombadas pelo município, disponível no site da prefeitura municipal, não se encontra nenhuma edificação com características Art Déco, o que demonstra uma relativa incompreensão dos poucos estudos sobre essa arquitetura em Passo Fundo, a despeito do grande número de edificações construídas nesse léxico.

É interessante estabelecer uma comparação com outras legislações municipais, como a da cidade de Bento Gonçalves/RS. O parágrafo $3^{\circ}$ do Artigo 90 de seu Plano Diretor (2018) aponta que:

$\S 3^{\circ}$. É considerado patrimônio histórico e cultural edificado os imóveis integrantes do inventário do Patrimônio Cultural Edificado do Rio Grande do Sul (1994-1996) e os conjuntos formados pelas sedes comunitárias e edificações com mais de $\mathbf{5 0}$ anos no entorno de bens culturais inventariados (BENTO GONÇALVES, 2018, grifo nosso).

Podemos notar a preocupação dessa cidade em considerar as edificações com mais de 50 anos no entorno de bens culturais inventariados como patrimônio histórico-cultural da cidade. Ou seja, partem da ideia de um conjunto de valor histórico e não de um monumento isolado; nas palavras de Edelweiss (2016) esse conjunto faz parte das ações contemporâneas de preservação.
Essa conjuntura denota a importância de se promover uma ampliação do conceito de patrimônio cultural. Segundo CASTRIOTA (2009) o termo "patrimônio" quando se refere a um objeto arquitetônico passa por uma visão restrita e delimitada frente a uma concepção contemporânea tão ampla que tende a contemplar a gestão do espaço como um todo.

Para tanto, para se pensar hoje em preservação de um artefato faz-se importante considerar o alargamento do conceito patrimônio. Esse conceito deve ser pensado sob algumas variantes representativas da materialidade e imaterialidade cultural, tais como: a memória, a história, os espaços, os documentos, as imagens, as palavras, as construções, a paisagem. Tal ensejo, significa que a medida em que se amplia o conceito de patrimônio, torna-se necessário também a ampliação dos instrumentos de (re)conhecimento e análise, com a incorporação das atuações dos mais diversos profissionais e da própria população, usuária e produtora do patrimônio. É necessário, assim, "criar uma cultura de preservação participada com a sociedade que, afinal, é o fim último da preservação: pois não se preservam apenas coisas, preservam-se coisas para as pessoas, as chamadas gerações futuras" (INOUE, 2018, p. 284). 


\section{Considerações Finais}

Diante da contextualização sobre a arquitetura Art Déco, que confirma sua significativa presença nos processos de verticalização e modernização de diversas capitais brasileiras e de muitas cidades de pequeno e médio porte, como Passo Fundo, e analisando-se o contexto por meio do qual o Art Déco foi inserido na paisagem da cidade, mostrouse a relevância dessa arquitetura na modernização e no início da verticalização da cidade, particularmente em sua área central.

Esse léxico arquitetônico esteve presente em diferentes tipologias na cidade. Podendo identificar características Art Déco em clubes sociais, cinemas, instituições, residências e edifícios de uso misto (residencial e comercial), porém essas edificações não são reconhecidas como de valor patrimonial para a cidade, acarretando ao longo do tempo a descaracterização desse conjunto por parte dos proprietários ou locatários, principalmente quando passam a ter um uso comercial.

O patrimônio não deve ser identificado sob uma dimensão museificadora do objeto, engessando o artefato de modo que ele não possa ser usado. Ao contrário, o reconhecimento de um objeto como de valor patrimonial deve permitir que ele seja ativo, seja memória na cidade. A dimensão de memória que se imagina é aquela pensada por Pierre Nora, ou seja, como um elo vivido no presente.
A história das cidades se conta por meio de sua paisagem urbana e de sua constante mutação. Conquanto, para que a história não se perca (ou se torne uma representação do passado) é fundamental a preservação desse conjunto arquitetônico, não necessariamente por meio de instrumentos como o tombamento, conforme foi analisado, mas de forma a integrar a memória do cidadão passo-fundense em seu cotidiano.

O reconhecimento de conjuntos ou edificações como de interesse histórico e cultural para a cidade, conjuntamente com diretrizes norteadoras para uso dessas edificações, garantem sua conservação e as mantêm atuantes no cotidiano, sem necessidade de tornar esses bens museus, centros culturais, ou algum outro uso por meio do qual a sociedade não se aproprie do espaço democraticamente. 


\section{Referências}

ACENTÚA-SE, em Passo Fundo, uma fase de importantes construções que, sobremaneira, contribuirão para o embelezamento e progresso da cidade. O Nacional, Passo Fundo, p. 3, 28 abril 1942. Disponível no Arquivo Histórico Regional de Passo Fundo.

ALMEIDA, Caliane Christie Oliveira de; DINIZ, Pedro Henrique Carretta. Cenário déco e comércio local: a expressividade do Arte Déco e o impasse da publicidade em edificações históricas no centro comercial de Passo Fundo-RS. In: XI Mostra de Iniciação Científica e Extensão Comunitária e X Mostra de Pesquisa de Pós-Graduação IMED 2017. Passo Fundo. Anais... Passo Fundo: IMED, 2017.

ALMEIDA, Leonardo Augusto de. Políticas patrimoniais no Brasil: um estudo sobre o Conselho Deliberativo do Patrimônio Cultural do Município de Ubá - Minas Gerais. 2017. 149 p. Dissertação (Mestrado) - Faculdade Federal de Viçosa, Minas Gerais, 2017.

ALMEIDA, Eneida. Inventários e processos de patrimonialização: o caso da Vila de Paranapiacaba. Revista Patrimônio e Memória, Assis, v. 14, n. 2 , p. 323-344, jul-dez. 2018. Disponível em: http:// pem.assis.unesp.br/index.php/pem/article/view/793. Acesso em: 14 jun. 2019.
BENTO GONÇALVEZ. Lei complementar $n^{\circ} 200$, de 27 de julho de 2018. Dispõe sobre a ordenação territorial do município de Bento Gonçalves e sobre a política de desenvolvimento municipal e de expansão urbana, aprova o plano diretor municipal e dá outras providências. Bento Gonçalvez, 2018. Disponível em: http://ipurb.bentogoncalves.rs.gov.br/uploads/ downloads/Lei_Complementar_200.pdf. Acesso em: 09 mai. 2019.

CASTRIOTA, Leonardo Barci. Patrimônio cultural: conceitos, políticas, instrumentos. São Paulo: Annablume; Belo Horizonte: IEDS, 2009.

CONDE, Luiz Paulo Fernandez; ALMADA, Mauro. Panorama do Art Déco na arquitetura e no urbanismo do Rio de Janeiro. In: CZAJKOWSKI, Jorge (org.). Guia da arquitetura Art Déco no Rio de Janeiro. Rio de Janeiro: Casa da Palavra, 2000, p. $5-20$.

CORREIA, Telma de Barros. Art déco e indústria: Brasil, décadas de 1930 e 1940. Anais do Museu Paulista, São Paulo, v.16, n.2, p. 47-104, jul.-dez. 2008. Disponível em: http://www.scielo.br/scielo.php?script=sci_arttext\&pid=S010147142008000200003. Acesso em: 05 mai. 2018.

CORREIA, Telma de Barros. O art déco na arquitetura brasileira. Revista UFG, ano XII, n. 8, jul. 2010. Disponível em: https://www.revistas.ufg.br/re- 
vistaufg/article/view/48295/23636. Acesso em 05 mai. 2018.

EDELWEISS, Roberta Krahe. Cidade contemporânea, memória e preservação patrimonial: uma interpretação a partir das preexistências culturais. Oculum Ensaios, v. 13, n.1, p.153-162. 2016. Disponível em: file://C:/Users/letic/OneDrive/Documentos/ Mestrado/Eventos/Artigo\%20Revista/ Bibliografia/ 3220-10202-1-PB.pdf. Acesso em: 13 jun. 2019.

FEAR. FACULDADE DE ENGENHARIA E ARQUITETURA DA UNIVERSIDADE DE PASSO FUNDO. Estudo para tombamento de patrimônio arquitetônico, histórico e paisagem de Passo Fundo, conforme o inventário provisório de 2008: complementação do inventário em janeiro de 2012. Passo Fundo, 2012. [Projeto NADUC/UPF].

FERRETTO, Diogo. Passo Fundo: estruturação urbana de uma cidade média gaúcha. Dissertação (Mestrado em Arquitetura e Urbanismo). Universidade de São Paulo, Planejamento Urbano e Regional. São Paulo, 2012.

GOSCH, Luis Roberto Medeiros. Passo Fundo, de Saturnino de Brito ao Mercosul: projetos e imagens urbanas. Dissertação (Mestrado), Universidade do Rio de Janeiro, Rio de Janeiro, 2002.
INOUE, L.M. O patrimônio urbano e as Cartas Patrimoniais. Oculum Ensaios, v.15, n.2, p.271-286, 2018. Disponível em: http://periodicos.puc-campinas.edu.br/seer/index.php/oculum/ article/view/ 4054/2652. Acesso em 14 mar. 2020.

INSTITUTO BRASILEIRO DE GEOGRAFIA E ESTATÍSTICA. Panorama de Passo Fundo. Disponível em: https://cidades.ibge.gov.br/brasil/rs/passofundo/panorama. Acesso em 10 ago. 2018.

INSTITUTO DO PATRIMÔNIO HISTÓRICO E ARTístICO NACIONAL. Mário de Andrade. 2015. Disponível em: http://portal.jphan.gov.br/pr/noticias/ detalhes/1024/mario-de-andrade. Acesso em: 16 dez. 2018.

KNACK, Eduardo Roberto Jordão. As comemorações do centenário de Passo Fundo e a construção do imaginário de capital do planalto em 1957. In: XXVII Simpósio Nacional de História, Rio Grande do Norte. Anais... Natal: ANPUH, 2013. Disponível em: http://www.snh2013.anpuh.org/resources/anais/ 27/1364363051_ARQUIVO_AscomemoracoesdocentenariodePassoFundoeaconstrucaodoimaginariodecapitaldoplanaltoem1957.pdf. Acesso em: 18 jul. 2019. 
KRAMER, Mara; WAIHRICH, Lorena Postal. Ar- MACHADO, Ironita P.; MIRANDA; Fernando B. Sequitetura Urbana de Passo Fundo: 1865-1965. vero de. Passo Fundo: presentes da memória. Rio

KÜMMEL, Márcia Barroso. Estudo sobre o art NORA, Pierre. Entre memória e história: a probledéco em Santa Maria/RS: o caso da avenida Rio mática dos lugares. PROJETO HISTÓRIA: REVISBranco e seu patrimônio edificado. 2013. Disserta- TA DO PROGRAMA DE ESTUDOS PÓS-GRADUção (Mestrado em Patrimônio Cultural - Área de ADOS DE HISTÓRIA, São Paulo, v. 10, s/n, jul.Concentração: Arquitetura e Patrimônio Material) - dez. 1993, p. 7-28. Disponível em: https://revistas.Universidade Federal de Santa Maria, Santa Maria, pucsp.br/index.php/revph/ article/view/12101. AcesRS, 2013. so em: 19 jul. 2019.

LECH, Osvandré; CZAMANSKI, Deoclides; CZAMANSKI, Ronaldo. Passo Fundo: memória e fotografia. 2. ed. Passo Fundo: Pe. Berthier, 1999.

LEMME, Arie Van de. Guia de arte déco. Lisboa: Editorial Estampa, 1996. 128 p.

LORENZI, Letícia Regina; DINIZ, Pedro Henrique Carretta; ALMEIDA, Caliane Christie Oliveira de; PICCINATO JUNIOR, Dirceu. ART DÉCO E A CENTRALIDADE URBANA DE PASSO FUNDO/ RS - BRASIL: impactos do crescimento socioespacial e da mudança de uso no repertório local. In: Seminário Docomomo Brasil, 13., 2019, Salvador. Anais [...]. Salvador: UFBA, 2019. Disponível em: http://www.inscricoes13docomomobrasil.ufba.br/. Acesso em 15 out. 2019.

PASSO FUNDO. Lei $n^{\circ} 2997,06$ de janeiro de 1995. Dispõe sobre a proteção do patrimônio histórico-cultural, paisagístico e natural do município de passo fundo e dá outras providências. Passo Fudo, RS. Disponível em: https://leismunicipais.com.br/al rs/p/passo-fundo/lei-ordinaria/1995/299/2997/leiordinaria-n-2997-1995-dispoe-sobre-a-protecao-dopatrimonio-historico-cultural-paisagistico-e-natural-

do-municipio-de-passo-fundo-e-da-outras-providencias. Acesso em: 11 jul. 2018.

PASSO FUNDO. Decreto $n^{\circ} 134,2013$. Regulamenta o artigo $2^{\circ}$ da lei $n^{\circ} 2997,06$ de janeiro de 1995, instituindo o livro tombo e dá outras providências. Passo Fundo, RS. Disponível em: https://leismunicipais.com.br/a/rs/p/passo-fundo/decreto/ 2013/13/134/decreto-n-134-2013-regulamenta-o-ar- 
-tigo-2-da-lei-n-2997-06-de-janeiro-de-1995-instituindo-o-livro-tombo-e-da-outras-providencias. Acesso em: 11 jul. 2018.

PISSETI, Rodrigo Fernandes; SOUZA, Carla Farias. Art Déco e Art Nouveau: confluências. Revista Imagem, Caxias do Sul, v.1, n.1, jun.-dez. 2011, p. 17-24. Disponível em: http://revistaimagem.fsg.br/ arquivos/artigos/artigo72.pdf. Acesso em: 02 mai. 2018.
SALVADOR, Sabrina Carnin. As edificações art déco na paisagem urbana: um estudo de caso em Criciúma - SC. 2012. 138 p. Dissertação (Mestrado em Arquitetura e Urbanismo) - Faculdade de Arquitetura e Urbanismo, Universidade Federal de Santa Catarina, Florianópolis, SC, 2012.

SEGAWA, Hugo. Arquiteturas no Brasil 19001990. 3. ed. São Paulo: EDUSP, 2014. 323 p. 